\title{
Pesquisando o ensino contemporâneo da arte contemporânea
}

Carine Betker ${ }^{*}$

Resumo: Este artigo apresenta questôes referentes ao ensino da arte na atualidade. Pretende analisar como a arte contemporânea tem sido abordada em sala de aula, apontando possíveis diferenças e/ou relações entre o ensino da arte na contemporaneidade e o ensino da arte contemporânea. Através do estudo de publicações recentes (2009 e 2010) dos anais da ANPAP e ANPED sobre o assunto, constata-se que a produção está, em sua maioria, concentrada na formação docente da área. Os demais trabalhos versam sobre uma multiplicidade de temas, sendo que muitos deles giram em torno de reflexôes sobre a prática do ensino da arte, em diferentes níveis de ensino. É com base na seleção de alguns desses artigos, que estudam especificamente a temática da arte contemporânea, que desenvolvo o presente estudo.

Palavras-chave: Ensino da arte; Arte contemporânea; ANPAP; ANPED.

Abstract: This paper presents issues related to the teaching of art today. Intends to examine how contemporary art has been addressed in the classroom, pointing to possible differences and / or relationships between teaching and education in contemporary art contemporary art. Through the study of recent publications (2009 and 2010) and the Annals of ANPAP ANPED on the

* Professora de Artes Visuais da Rede Municipal de Ensino de Porto Alegre. Graduada em Artes Plásticas - Licenciatura. Especialista em Metodologia do Ensino da Arte. Mestra em Educação pela PUCRS. E-mail: carinebetker@hotmail.com. 
subject, it appears that production is, mostly concentrated in the area of teacher training. The other papers deal with a multiplicity of themes, and many of them turns around reflections on the practice of art education at different educational levels. It is based on the selection of some of these articles, specifically studying the theme of contemporary art that I develop this study.

Keywords: Teaching art; Contemporary art; ANPAP; ANPED.

\section{Introdução}

A pesquisa para a elaboração deste artigo partiu de uma leitura flutuante dos anais da ANPEd - Associação Nacional de Pós-Graduação e Pesquisa em Educação -, e por encontrar poucos artigos, no GT 24 - Educação e Arte -, relacionados com o assunto específico da Arte Contemporânea, parti para uma busca nos anais da ANPAP - Associação Nacional de Pesquisadores em Artes Plásticas -, mais especificamente no Comitê de Ensino de Artes Visuais, encontrando um número considerável de artigos para elaborar um texto de análise de como a Arte Contemporânea tem sido estudada em sala de aula, especialmente no Ensino Básico, bem como busco fazer um mapeamento de quais são os focos dos discursos existentes sobre o tema. Há uma série de publicações, especialmente livros, editados com base no ensino da arte, especialmente os de Ana Mae Barbosa, Miriam Celeste Martins, entre outros autores, mas a opção por pesquisar nestes periódicos acadêmicos diz respeito à atualidade das pesquisas, com problemas e questionamentos ainda muito latentes, e mais próximos da realidade. Realizo, assim, um desvio quanto às publicações já consagradas da área na busca de outros olhares sobre o Ensino da Arte. Após essa pesquisa nos Anais da ANPED e ANPAP, realizei uma busca no banco de Teses e Dissertações da CAPES, onde as publicações encontradas foram dos mesmos 
autores dos artigos mais significativos, o que fez com que eu acabasse optando por trabalhar apenas com os artigos.

Durante a pesquisa, foram encontrados em torno de 21 artigos que mantinham relação com o tema e, após esta primeira seleção, foi realizada a leitura dos mesmos, o que resultou na seleção dos seguintes artigos: Comitê de Educação em Artes Visuais: uma análise das questões de pesquisa da ANPAP 2008, de Irene Tourinho; Ensino da Arte Contemporânea possibilitando mudanças nos modos de percepção da arte, de Greice Cohn; O contexto e a mediação da recepção na Arte Contemporânea, de Vera Rodrigues de Mendonça; Mediação educacional e sistema da arte, de Cayo Honorato; Arte contemporânea no contexto escolar: ausências e resistências, de Kelly Bianca Clifford Valença; Jakobson, Duchamp e o ensino de Arte, de Terezinha Losada; A Arte na escola e o conbecimento do sensivel, de Josélia Schwanka Salomé; Pixação como trabalho de conclusão de curso (TCC): Corajosos investimentos filosóficos para o ensino da arte, de Gustavo Coelho; Pichação e grafite: reverberações educacionais, de Valdemar Schultz; (Re)Lendo o espaço nas ondas imaginárias do graffiti: contribuiçôes para uma arte/educação contemporânea, de Cláudia Mariza Mattos Brandão; Contágios entre arte e midia no ensino da arte, de Analice Dutra Pillar e A complexa busca pela transdisciplinaridade no ensino da arte, de Sandra Regina Ramalho e Oliveira e Sandra Conceição Nunes. Aqui faz-se necessário o esclarecimento de que a pesquisa se voltou para proposições que buscam refletir o Ensino de Arte centrado nas Artes Visuais.

Com relação à metodologia da pesquisa, é fundamental citar o artigo de Irene Tourinho Comitê de educação em artes visuais: uma análise das questões de pesquisa da ANAP 2008, no sentido de que proporcionou um direcionamento da pesquisa, servindo como referência metodológica, tendo em vista que apresenta justamente os questionamentos propostos pelos pesquisadores através dos trabalhos de 2008, e foi a partir da leitura de Tourinho que optei por subdividir o texto em três tópicos fundamentais, que serão explicitados após o prêambulo sobre a Arte Contemporânea. 


\section{Prêambulo: a arte contemporânea}

Desde os anos 1960, começaram a surgir artistas e obras que buscam apresentar ao público um modo diverso de perceber e conceber a arte. É neste momento que se inicia a transição da arte moderna para a contemporânea, ou Pós-Moderna, como alguns autores irão classificar, variando de acordo com o modo de compreensão das mudanças também ocorridas na sociedade nas últimas décadas do século XX, ou seja, cada vez mais busca-se um diálogo com a arte produzida em nosso tempo e os modos de vida que levamos. Há uma articulação nas criações de modo a proporcionar uma maior participação/interação do público com as obras, o que exige uma postura diferenciada do espectador. Para o teórico Fernando Cocchiarale " $[\ldots]$ a arte contemporânea pode estar em vários lugares simultaneamente desempenhando funções diferentes. Mas, o principal de tudo isso são os novos tipos de relação que ela nos faz estabelecer." (COCCHIARALE, 2006, p. 66). Paralelo a essas mudanças ocorridas no campo artístico, houve também uma série de mudanças com relação ao ensino da arte, passando de uma visão tecnicista para espontanesta, e, atualmente é concebida como área de conhecimento com conteúdos específicos, superando a concepção superficial que era vigente. Desde a promulgação da lei 9394/96, que estabelece diretrizes para o ensino da arte, e também da elaboração da proposta triangular, de Ana Mae Barbosa, que é de utilizada de forma indireta como referência nos PCNs - Parâmetros Curriculares Nacionais - busca-se uma série de aproximaçôes entre o ensino da arte e o cotidiano dos alunos, interligando durante as aulas o conhecer, o fruir e o poetizar. Por vezes, essa busca por aproximação se dá com a utilização da arte contemporânea como conteúdo das propostas educativas, sendo que a abordagem de outros momentos da história da arte permanece como integrante dos programas de ensino.

Como forma de conhecer melhor de que maneira a arte contemporânea tem sido abordada no meio acadêmico, parti 
para análise dos artigos selecionados. Havia outros que também discorriam sobre o assunto, mas com um olhar mais voltado para a reflexão acerca de práticas educativas bastante pontuais, optei, então, por deixá-los para uma análise posterior. As proposições presentes nos textos escolhidos acabam colaborando para o pensamento sobre questões conceituais que também se articulam com a prática que vivencio em sala de aula, colaborando para o processo de análise, e conectando-o com a realidade. Assim, as principais proposições/questôes referenciais para pensar a arte contemporânea, relacionada com o ensino, são: 1) "Atenção: percepção requer envolvimento" - Observações sobre Mediação, Público e Percepção; 2) Conhecimento Sensível e Contexto Escolar; 3 ) Arte e Comunicação: a cidade como suporte. Esses tópicos funcionam como elementos norteadores da pesquisa.

Figura 1: Primeira parte - "Atenção: percepção requer envolvimento": observações sobre mediação, público e percepção

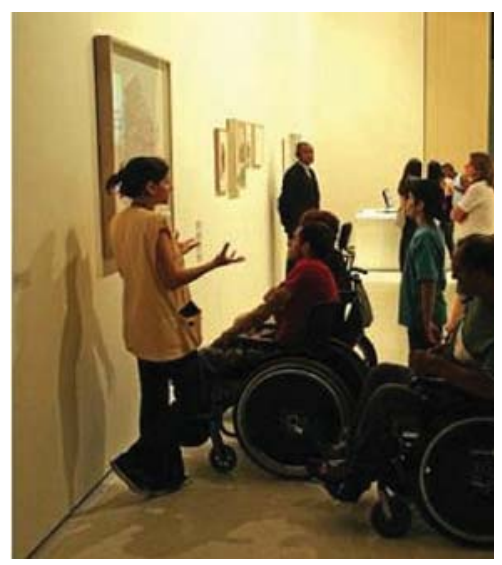

Fonte: Registro de um momento de visita mediada, realizada na exposição de Jorge Macchi $-6^{\circ}$ Bienal do Mercosul. Disponível em: <http://www. dasartes.com/site/index.php?option $=$ com_content\&view $=$ article\&id $=119 \&$ Itemid $=224 \&$ limitstart $=2>$ Acesso em: 13 jun. 2011 . 
Marco Polo descreve uma ponte, pedra por pedra.

- Mas qual é a pedra que sustenta a ponte?-pergunta Kublai Khan.

- A ponte não é sustentada por esta ou aquela pedra, responde Marco, mas pela curva do arco que estas formam.

Kublai Khan permanece em silêncio, refletindo. Depois acrescenta:

- Por que falar das pedras? Só o arco me interessa.

Polo responde:

-Sem pedras o arco não existe.

(CALVINO, 2003, p. 81)

A percepção é elemento fundamental para que aconteça o estabelecimento de vínculo entre a arte e o público, é através dela que a obra passa a fazer sentido e pode gerar uma experiência estética. Diante das inúmeras possibilidades de contato com a arte que temos hoje em dia, tanto com as grandes ou pequenas exposições, bienais, galerias quanto com propostas diferenciadas de curadoria, por vezes em espaços alternativos como bares, lojas, cinemas e mesmo espaços públicos instituídos como destinados para a arte, como as praças e os parques, ou então a própria rua, é necessário pensar como se dá esse diálogo entre as obras e o público. Esse processo, atualmente, passa a envolver a figura do mediador, que tanto pode ser o próprio professor ou o profissional que atua em espaços culturais, assumindo um papel peculiar, pois é ele quem deve instigar o público a perceber a obra, construir sua própria leitura, atuando como uma "ponte" entre esses dois polos do abismo - entre a arte e o espectador. Mas essa ponte exige uma série de conhecimentos para ser construída, há uma complexidade que envolve a sua tessitura, para suportar o fluxo de idas e vindas por sobre sua malha. Miriam Celeste Martins apresenta a seguinte definição de mediador:

O termo "mediação", segundo o dicionário, significa o ato ou efeito de mediar. É uma intervenção, um intermédio. Pode ser visto envolvendo dois pólos que dialogam por meio de um terceiro, um mediador, um medianeiro, o que ou aquele que executa os desígnios de intermediário. 
Mas, a mediação ganha hoje um caráter rizomático, isto é, num sistema de inter-relaçôes fecundas e complexas que se irradiam entre o objeto de conhecimento, o aprendiz, o professor/monitor/mediador, a cultura, a história, o artista, os modos de divulgação, as especificidades dos códigos, materialidades e suportes de cada linguagem artística... Mediação/intervenção que mobiliza buscas, assimilações, transformações, ampliações sensíveis e cognitivas, individuais e coletivas, favorecendo melhores qualidades na humanização dos aprendizes - alunos e professores. (BARBOSA, 2003, p. 56)

Neste momento, cito o abismo como uma metáfora, no sentido de que há um distanciamento entre arte e público, mas que ao mesmo tempo existe o desejo de alcançar um o lado do outro, descobrir o que existe nas terras que estão do outro lado, mas por vezes o medo e outros fatores acabam impedindo que essa experiência exploratória aconteça. É preciso que existam pontes e elas podem ser de diferentes concepções e formas, porém o que importa é que elas existam. Além disso, na base há a conexão, um lado e o outro são feitos do mesmo extrato, mesma terra, que acolhem na maioria das vezes um riacho que está em fluxo constante. E, acredito que a relação público e arte é configurada dessa forma. No fundo, as obras surgem do cotidiano, das vivências dos artistas que também são público, em diferentes momentos, de outros artistas, e que estão o tempo todo em relaçôes de troca com as pessoas que circulam cotidianamente, é um ciclo de trocas, pois é com o olhar do público que a obra adquire sentido, e o retorno desse olhar do público, respondendo com críticas e interações que alimenta a renovação do ciclo. Na concepção de Archer "[...] a arte é um encontro contínuo e reflexivo com o mundo em que a obra de arte, longe de ser o ponto final desse processo, age como iniciador e ponto central da subseqüente investigação do significado" (ARCHER, 2001, p. 236)

Voltemos nossa atenção para a análise do modo como a arte tem sido apresentada hoje em dia. Com sua diversidade de linguagens e meios, podemos perceber momentos e espaços distintos, para que o contato entre arte e público aconteça e, 
consequentemente, mediações com caráter diversificado são fundamentais. Se observarmos como os espaços têm-se configurado atualmente, iremos constatar a presença de três grandes eixos, com sistemas e características próprias, em que o público entra em contato com a arte.

Pode-se começar pelos espaços instituidos da arte, que contemplam os museus, as galerias, bienais, portanto, as exposições em que há toda uma estrutura curatorial pensada justamente para aproximar arte e público, com estratégias para o estabelecimento de diálogos e reflexões acerca do que está sendo exposto, o mediador assume um posto mais definido neste setor.

Em seguida vamos ter o sistema de ensino da arte, o que corresponde às escolas, podendo estar ligado tanto nas redes formais como nas informais de ensino. Pode-se dizer que muda o foco da mediação, pois entram em cena outros objetivos, que ultrapassam a experiência estética, voltando-se para a busca da formação do individuo dentro de um programa mais amplo de construção de conhecimento; aqui o mediador, na verdade, é o próprio professor.

Depois vamos ter os espaços informais, das ruas, a cidade vista como um sistema, em que o mediador acaba sendo o próprio espaço urbano, com todo o excesso de pessoas e informações, tanto visuais quanto sonoras, provenientes e características deste contexto. Não há a figura do mediador personificada, mas sim evocada por toda a bagagem cultural do indivíduo, que percebe as intervenções e acaba elaborando uma leitura muito particular do que está sendo visto, vivenciado.

Ao olharmos para um histórico da atividade da mediação, iremos constatar que é bastante recente, e ainda sofre algumas resistências, pois é considerada superficial e dispensável. Sobre a atividade específica da mediação da produção contemporânea, a pesquisadora Vera Rodrigues vai destacar que:

Todos esses esforços de mediações nas recepções das obras de arte são desconsideradas, ainda, por alguns agentes desse circuito porque pensam que tais ações são desnecessárias para a percepção das obras 
ou, simplesmente, recusam tais atividades. De qualquer modo, é fato que se começa a ser desvelado o valor da mediação na relação da obra com seu espectador, minimizando inclusive o preconceito que envolve o binômio arte/educação. [...] Se por um lado alguns rejeitam as mediações por acreditarem em uma arte que fala por si só, por outro, há aqueles que, como nós, querem dinamizar as relações artísticas com o público, por meio de ações mediadoras. A arte não fala por si porque não é uma entidade isolada, mas uma ocorrência que deriva de um conjunto de ações humanas articuladas que contribuem para comunicar o seu modo de existência. Podemos afirmar que para haver a comunicação é necessária a troca e a interação: um modo não preconceituoso e aberto aos sentimentos e às sensações tão requisitadas pela arte contemporânea que busca uma relação densa e uma recepção ativa. (RODRIGUES, 2009, p. 3955)

A mediação surge como uma resposta frente a essa mudança de postura exigida pela arte na contemporaneidade, em que o espectador é convocado a ter uma postura ativa diante da obra, e não só ativa, mas também crítica e reflexiva. Neste momento entra em cena o mediador como a figura que irá provocar ainda mais perguntas, e o melhor de tudo: sem dar as respostas, pois elas devem ser buscadas pelo próprio espectador.

Por sua vez, Cayo Honorato, em seu texto que discorre sobre o papel da mediação, vai debater o desmerecimento desta função, apresentado em alguns ambientes, como já fora apontado anteriormente. Apesar da crescente atenção que tem sido destinada ao trabalho do mediador em grandes exposições, ainda não é uma participação efetiva do mediador como influente no sistema da arte, segundo ele:

Todavia, quanto à questão sobre a participação da mediação educacional no processo de legitimação do que seja arte, não me parece que ela, em comparação com as demais instancias do sistema, tenha até o momento uma posição muito decisiva. Para tanto, há certamente instancias de maior poder ou prestígio: o museu, a curadoria, a história da arte, a crítica, o mercado, etc. [...] Mas tudo se passa como se a mediação recebesse pronto o que seja arte, para então torná-la mais próxima e acessível a um público abrangente. (HONORATO, 2010, p. 2005) 
Este autor vai estruturar sua argumentação no sentido do quanto é importante a participação do público para que a obra seja plena, que o tornar-se obra seja efetivo, para que haja uma percepção ativa (2010, p. 2006), é neste momento que entra a defesa da importância do mediador neste processo, que não é abordado de modo direto, mas elucidado através de tópicos que irão articular justamente a relação problemática público/arte, expressa nos subtítulos: $O$ artista e o público, A potência do público e O incontornável sistema. É no segundo tópico que o autor nos convoca a pensar sobre a necessidade do público para a existência da obra, em suas palavras:

O fundamental dessas considerações me parece o seguinte: não é somente para o público que a arte existe, mas também por ele. E não porque lhe seja franqueado "participar" ou "interagir" com a obra, nem porque ele produz uma demanda de necessidades a serem satisfeitas. Tal como adverte o artista catalão Antoni Muntadas, "a percepção requer empenho". Aliás, o público que faz com que a obra de arte aconteça como arte não se constitui de indivíduos que se confirmam empiricamente, tal como existem, mas daqueles que se expõem a um movimento de transformação que os excede. (idem, p. 2007)

Pensar que uma pessoa pode vivenciar uma experiência estética, entrar em contato com uma obra e a partir de então passar a perceber algumas coisas de um modo diferente daquele que já percebia anteriormente, sentir que algo mudou, ou que algo pode ser mudado; acredito que esse seja o objetivo maior de toda a discussão acerca das ações da mediação, bem como dos processos educativos voltados para a arte.

Alguns dos aspectos da mediação, como a relação entre arte e público, e principalmente sobre percepção, também podem ser sentidos nas experiências relatadas por Greice Cohn. A autora faz uma excelente análise de experiências realizadas com alunos do ensino médio, partindo da arte contemporânea, neste caso, a própria pesquisadora torna-se uma mediadora. Ela problematiza como as mudanças na arte, e nos modos de percepção da arte, acabam transformando os procedimentos de ensino. Para ela: 
É neste espaço relacional entre o aluno e o mundo que se situa a arteeducação na atualidade. $\mathrm{O}$ ensino da Arte na contemporaneidade se propõe relacional, múltiplo, participativo, inclusivo e questionador, de forma que possa proporcionar ao seus alunos uma atitude ativa, crítica e reflexiva diante do mundo. Remete-nos, assim, à arte contemporânea, cuja abordagem se dá no espaço relacional, dialógico e indagativo existente entre obra e espectador, provocando neste uma atitude ativa, crítica e reflexiva diante de suas obras. (COHN, 2009, p. 3323)

Dessa forma, percebe-se que o ensino da arte deve ser um espaço de debate sobre a produção contemporânea de arte, pensando suas relações e possibilidades de troca com o público, e neste caso um público bastante específico, ligado ao meio escolar. Vale ressaltar que, nessa citação anterior, surge novamente a referência à mudança de atitude que deve ser adotada pelo espectador e isso é válido não apenas para os alunos citados por Cohn, mas para o público de um modo geral. Este aspecto também é recorrente nos textos de outros autores pesquisados anteriormente.

Ainda pensando essa questão do contato com a obra, Pillar fala que "Através da nossa interação com os textos da arte e da mídia, muitas vezes experimentamos sensações, emoções, pensamentos provocados por este contato direto, que nos contagia, nos transforma.” (PILLAR, 2010, p. 1930) Podemos pensar nesse momento de interação como um momento frutífero para o desenvolvimento de um trabalho de mediação, elaborado muito no sentido de instigar ainda mais o espectador. E é pensando nesta característica da arte, de movimentar sensaçôes, é que podemos dar sequência nesta investigação sobre as possibilidades da arte contemporânea no ensino. 


\section{Conhecimento sensível e contexto escolar}

Figura 2- Segunda Parte- Conhecimento sensível e contexto escolar

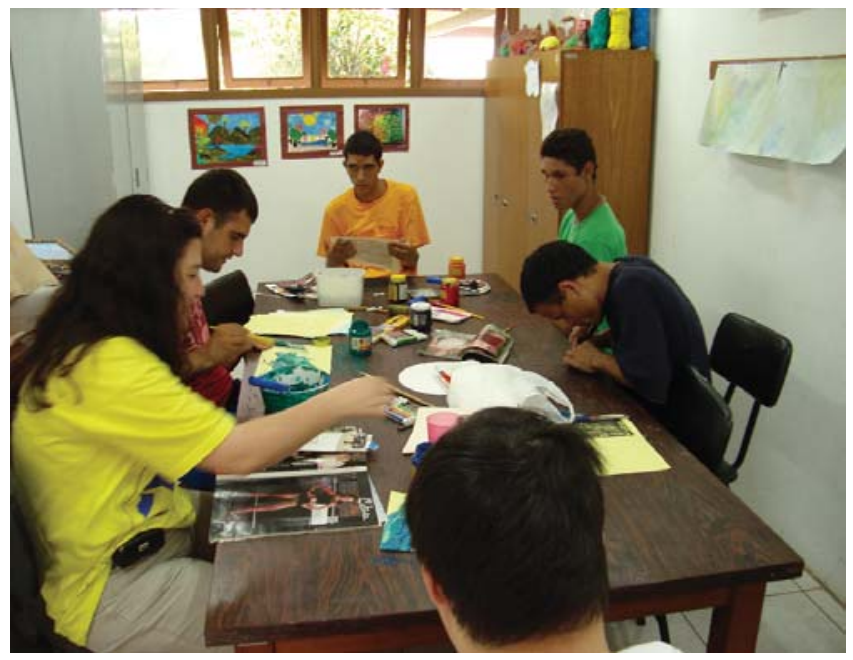

Fonte: Arquivo pessoal de Carine Betker.

Podemos encontrar vasta argumentação sobre a necessidade de valorização do conhecimento sensível, que seria estimulado ou proporcionado pelo ensino da arte. Este conhecimento sensível e sua relação com a educação é descrito por Duarte Jr. de um modo bastante elucidativo:

Assim, a educação da sensibilidade, o processo de se conferir atenção aos nossos fenồmenos estésicos e estéticos, vai se afigurando fundamental não apenas para uma vivência mais íntegra e plena do cotidiano, como parece ainda ser importante para os próprios profissionais da filosofia e da ciência, os quais podem ganhar muito em criatividade no âmbito de seu trabalho, por mais racionalmente "técnico" que este possa parecer. Uma educação que reconheça o fundamento sensível de nossa existência e a ele dedique devida atenção, proporcionando o seu desenvolvimento, estará, por certo, tornando mais abrangente e sutil a atuação dos mecanismos lógicos e racionais de operação da consciência humana. (DUARTE, 2003, p. 171) 
A arte contemporânea surge, também, para a educação, como uma proposta de trabalho que pode criar um modo de percepção mais sensível. Esse é um discurso já consolidado com referência ao ensino da arte, mas ainda mantém-se atual. Especialmente como alternativa frente à anestesia em que vivemos, na qual não há tempo para nada, as informações, imagens e os apelos são vastos, mas todos são vistos de modo superficial, muitas vezes não sendo percebidos em seu todo. Então, a arte contemporânea, com uma variedade de propostas, sensoriais inclusive, seria um modo de envolver um pouco mais o corpo como um todo e nos convoca para uma reflexão mais profunda sobre as experiências que vivemos.

Parece ser um contrassenso falar em anestesia dos sentidos diante do contexto da arte contemporânea, que procura trazer o espectador cada vez mais para dentro da obra, tanto de modo interativo como perceptivo, e muitas vezes como colaborador na elaboração da obra. Mas olhando atentamente para o cotidiano podemos perceber que vivemos realmente uma série de anestesias. Essa característica pode ser constatada quando, por exemplo, vemos imagens de notícias violentas, provenientes dos mais diversos lugares, sejam eles muito próximos ou muito distantes, e isso acontece na maior parte do tempo. Veiculadas na mídia em sua maioria, elas são agressivas, porém nem sempre nos comovem, não sabemos muito bem porque, mas é como se de tão repetidas se tornassem banais, ou até mesmo naturais.

O oposto também vai acontecer, com situações em que o fato de vermos uma imagem choca muito mais que o fato que acontece repetidas vezes no cotidiano, mas que no momento em que é transformado em imagem e deslocado para outro ambiente acaba gerando uma reação diversa. É como se necessitasse de uma série de aparatos para que a realidade seja visualizada, como nos diz Guy Debord "[...] o espetáculo não é um conjunto de imagens, mas uma relação social entre pessoas, mediada por imagens.” 
A pesquisadora Josélia Salomé argumenta para a importância do conhecimento sensível no ensino da arte, como sendo um modo de pensarmos na educação de forma a constituir uma sociedade mais humanizada, frente às dicotomias que nos afetam, e geram distanciamentos entre os indivíduos e os trabalhos que desenvolvem, perdendo assim a identidade. Em suas palavras:

Daí a necessidade da arte-educação ser estudada dentro da sociedade capitalista, como um processo que permitirá ao homem a sua humanização, possibilitando acesso aos conhecimentos elaborados pelo homem no percurso de sua história, possibilitando assim humanizar-se nesse processo, percebendo-se agente do meio social onde vive. [...] a arte na escola é uma atividade criadora aliada ao conhecimento artístico que, quando trabalhada como meio de formação dos sentidos humanos, propiciará o desenvolvimento de uma atitude crítica frente o mundo que cerca esse homem. (SALOMÉ, 2009, p. 3378-3379)

O conhecimento sensível aqui é tratado não apenas no âmbito sensorial, muito relacionado com as sensações provocadas pelo contato com obras de arte que nos envolvem fisicamente, mas sim no sentido de um conhecimento a ser construído, que envolve a produção de subjetividades. Com isso, retornamos à questão anteriormente discutida, de que a arte requer envolvimento, pois ultrapassa o modo contemplativo de apreensão da arte. Ainda sobre esse aspecto, podemos recorrer ao pensamento de Kelly Valença:

[...] é preciso que não confundamos imagem ou obra de arte com discurso. Os discursos e significados estão nos sujeitos e em suas respectivas relações com os artefatos. Logo, os significados não estão nos artefatos. Estes, não carregam discursos de forma que as pessoas possam olhar e 'alcançar' ou, ainda, adivinhar o que o artista quis 'passar' ou 'dizer'. Muito embora os artistas tenham intenções ao elaborarem seus trabalhos, isso não garante que as pessoas percebam em consonância com o pensamento criador, nem tão pouco significa que este pensamento elimine outras maneiras de interpretar. [...] quem olha, logo interpreta, é a nossa mente conectada às nossas experiências sócio-culturais. É 
assim que entram em cena nossos sentidos e nossos repertórios. (VALENÇA, 2009, p. 3407)

Essas pesquisadoras irão nos proporcionar em suas reflexões, um retorno ao entendimento do ser humano como um todo, em que andam juntas as dimensões: físicas, sociais, históricas, culturais e psíquicas, propondo-nos um ensino da arte que contemple essas dimensões, que busque o estabelecimento de diálogos entre essas diferentes dimensões do ser. De certa forma, é a centralidade no sujeito que vai tornar a percepção ativa e constituir os sentidos para ele sobre as experiências vividas.

O termo sentido pode surgir com inúmeras significações, dependendo do contexto em que é aplicado, e aqui neste texto foi utilizado pelo menos em duas dimensões diversas, mas que se unem justamente para construir uma totalidade em relação à percepção da arte, vamos ter as duas dimensões dos sentidos, tanto os relacionados com a dimensão simbólica da obra, no modo como iremos "compreender/significar" o que está sendo apresentado, como os sentidos sensoriais. De certa forma, essas duas dimensões estão presentes em todo o processo educativo, pois a construção do conhecimento só acontece quando há a interação entre eles; é preciso que a materialidade e a afetividade caminhem juntas. Como nos diz Duarte Jr. "[...] o mundo, antes de ser tomado como matéria inteligível, surge a nós como objeto sensível" (DUARTE, 2003, p. 13). E, assim, chegaremos aos modos como a materialidade do ambiente nos proporciona formas de comunicação, que nos tocam através de inúmeras sensações, e geram outros diálogos, como veremos a seguir. 
Figura 3 - Terceira Parte - Arte e comunicação: a cidade como suporte.

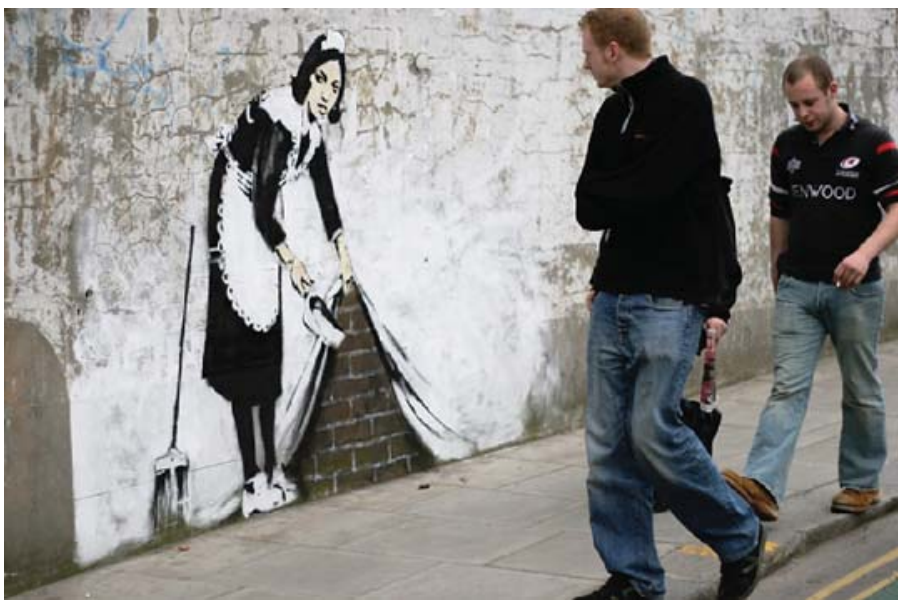

Fonte: Intrevenção urbana do artista Banksy - Londres. Disponível em: http://artsjournal.com/artropia/2011/02/banksy_loses_oscar_bid.html. Acesso em 13 jun. 2011.

Apesar das temáticas variadas, muitos artigos pesquisados evidenciam uma questão latente: o aspecto comunicativo da arte. Essa comunicação estabelece-se nos meios os mais diversos, indo desde projetos transdisciplinares, passando por estudos da cultura visual, estudos de teorias relacionadas com a semiótica e chegando a pesquisas de linguagens específicas como o grafite e a pichação (a grafia dos termos varia de acordo com o autor). Esses últimos, com uma presença marcante nas últimas reuniões da ANPED, constando de três trabalhos dedicados exclusivamente ao tema, o que não é algo muito comum. Esses artigos acabam por nos conduzir à vasta produção de arte contemporânea que problematiza o espaço urbano, utilizando a cidade como suporte para suas ações e intervenções. Pensar como o ensino da arte pode estar articulando a percepção de todos esses processos, híbridos por natureza que estabelecem pontos de diálogo com a cidade, fazem-se necessários neste momento. 
A comunicação pode ser pensada como uma relação que envolve as dimensões de espaço e tempo. Toda comunicação assume características específicas de acordo com o tempo histórico em que se vive, bem como só fará sentido inserida em um determinado espaço/lugar, criando diálogos em códigos que são a identidade daqueles lugares, portanto estreitamente ligados a eles. A leitura desses códigos, de certa forma, irá proporcionar uma interpretação do contexto social, entrando em cena não apenas os códigos verbais, mas também os de ordem sensível e visual. Nesse sentido, as palavras de Claudia Brandão são esclarecedoras:

A leitura visual do mundo viabiliza a compreensão de que realidade não se reduz a um conjunto de dados materiais ou fatos isolados. Ela favorece o reconhecimento dos substratos das atitudes sociais, reflexos de mentalidades e comportamentos. O exercício da contemplação possibilita perceberem-se as relações e inter-relações que constituem a vida social, ressaltando a importância da atividade simbólica para a compreensão de qualquer agregação social e suas particulares relações. (BRANDÃO, 2010, p. 2)

Em sua pesquisa sobre as contribuições da prática do grafite para arte contemporânea e seu ensino, Brandão (2010) acaba por nos conduzir a olhar para caminhos outros como prováveis alternativas para o ensino da arte, em que apresenta possibilidades muito mais centradas na observação do cotidiano, com suas imensas potencialidades, "[...]perceber o mundo através de suas manifestações cotidianas caracteriza processos educativos que transcendem a lógica do raciocínio científico e oportuniza a percepção sensível.” (Idem). Além da pesquisa de Brandão (2010) outros dois pesquisadores irão abordar a temática do grafite e da pichação, em trabalhos apresentados na $33^{a}$ reunião da ANPED, cada um com suas particularidades, mas que centralizam o foco da discussão sobre esses procedimentos de intervenção urbana.

Valdemar Schultz, em seu estudo sobre o grafite e a pichação, irá abordar o tema como um modo de "interação social" (SCHULTZ, 2010, p. 5), pensado no contexto de "protesto pacífico" (idem, p. 2) o que nos conduz à dimensão da comunicação 
presente nesses meios, com intenções as mais diversas, variando de acordo a autoria da intervenção e o espaço escolhido. É como Valdemar diz:

Pichações e grafites estão presentes pelos muros, portas de garagem, na fachada dos prédios, viadutos, postes, vagões, túneis, ruínas, monumentos e tantas outras superfícies disponíveis que possam servir de suporte. Incorporados à paisagem das metrópoles, a pichação e o grafite estão presentes tanto nas vias de circulação quanto nos espaços intransitáveis. Já que não se pode mais ignorar sua presença. (Ibidem, p. l)

Essa presença é fecunda para os debates em sala de aula, levando-nos a analisar a potencialidade de ambas as linguagens, grafite e pichação, e o pesquisador Valdemar aborda justamente essa dicotomia que existe na sociedade, em que geralmente se valoriza o grafite em detrimento da pichação. Sem emitir juízo de valor sobre o tema, pois, segundo ele, os dois procedimentos apresentam pontos em comum, tanto em suas origens como no caráter afirmativo de quem os cria. Pensando exatamente no caráter de expressão social, podem ser associados a uma necessidade de experimentação gráfica, presente inclusive nos espaços das escolas, nas palavras dele:

Com o apoio de instituições sociais, um número considerável de grafiteiros reivindica para si o status de artistas, enquanto que considera a pichação vandalismo. Em contra partida, alguns pichadores consideram a prática do grafite cooptada pelo sistema. O limite entre um estilo e outro é tênue e as tentativas de diferenciação correm o risco de valorizar uma prática em detrimento da outra. As pesquisas tendem a resistir às tentativas de classificação dos "tipos" de grafismos urbanos porque dão maior relevância ao tipo de interação social presentes em ambas as práticas. (Ibidem p. 5)

Por sua vez, Gustavo Coelho apresenta uma pesquisa mais complexa, que vai concentrar seus esforços especialmente sobre a pichação propondo-a como um diálogo entre as duas faces das cidades, entre o que é instituído e o que é marginal. Contrapondo inclusive com o grafite. Avançando na problematização sobre o ensino da arte, Coelho vai refletir sobre a questão no âmbito 
do ensino superior, desenvolvendo seu texto a partir da análise de um TCC totalmente baseado na pichação, trabalho este desenvolvido por um pichador-estudante de Belas Artes. Atitudes que geram polêmicas sempre são bem-vindas para a estruturação de debates acerca dos modos como a arte é absorvida pelo público e, no âmbito escolar, acredito que, independentemente de nível de ensino, acabam provocando uma reestruturação do pensamento acerca do instituído. O trabalho citado por Coelho busca justamente a ruptura dos limites existentes entre arte $\mathrm{e}$ vida e consequentemente podemos pensar em rupturas entre arte e educação.

Diferentemente de Schultz, que prima pela neutralidade, Coelho vai argumentar no sentido de uma potência maior para a pichação, definida assim em suas palavras:

Não se pode entender, portanto, a piXação, limitada à sua produção tipográfica, ao nome no muro, muito menos às suas reelaborações como estampas de roupas, outdoors ou estudos de design. A piXação, em sua completude não é apreensível numa exposição, numa foto que seja, ela só se completa no momento que é eXperienciada, vivida, em toda sua sedução e subversão, em todo peso carregado por aqueles que, ao escolhê-la como opção para ocupar o mundo, para escrever sua vida sem autorizaçôes, aceitam o fardo e o orgulho irônico de se apaixonarem pelo crime. (COELHO, 2010, p. 17-18)

De certa forma, seu texto, em tom poético, vai ser articulado totalmente de modo dual, sempre beirando o abismo entre uma face e outra do tema, transitando e questionando a legalidade e o crime, sendo guiado pela metáfora da cidade de Bersabeia, de Ítalo Calvino, que fala de uma cidade que teria uma irmã gêmea em seu subsolo, e esta seria possuidora de tudo o que havia de indesejável na cidade da superfície.

Observar o cotidiano, os espaços por onde circulamos e o que há neles, pensando as intervenções que existem ao nosso redor, como sendo materiais para a elaboração de propostas de ensino mais conectadas com a realidade são questões centrais desses artigos analisados. Para além da marca física que fica registrada no espaço urbano com as intervenções do grafite ou da 
pichação, existe outro aspecto fundamental, o de transitório, que pode estar associado à performance, conceito bastante explorado na arte contemporânea. Nessas ações de grafiteiros e pichadores, o processo de construção das imagens é tido como elemento constituinte da obra. Assim, o caráter efêmero do processo de realização, que pode ser definido como um "acontecimento", entra em diálogo com o que Archer fala sobre a performance dos anos 1970: "[...] uma arte que pudesse afirmar-se como tal ao negar o potencial de venda dos objetos carregava uma certa força política e ideológica contrária aos dogmas da economia capitalista de mercado" (ARCHER, 2008, p. 117).

Seguindo conectados com a temática do cotidiano, vamos ter os artigos com as propostas que analisam o ensino da arte pelo viés da visualidade, tema que já vem sendo estudado no âmbito do ensino da arte há algum tempo, principalmente desde os estudos da cultura visual, que originaram inúmeros trabalhos de pesquisa, em sua maioria baseados pelo pensamento de Fernando Hernàndez. Neste sentido, o artigo de Pillar denominado Contágios entre arte e mídia no ensino da arte, apresentado no $19^{\circ}$ encontro da APAP, vai ser referencial, pois, além de trazer esclarecimentos sobre visualidade, vai acrescentar o conceito de contágio, baseado em Landowski, para analisar situações de ensino/aprendizagem que utilizam como referência a mídia do desenho animado. Segundo Pillar:

A visualidade, como um texto híbrido que envolve arte, mídia e imagens do cotidiano, é, na contemporaneidade, objeto de estudo do ensino da arte. A teoria semiótica discursiva tem contribuído para a leitura da visualidade por prestar atenção, além do conteúdo, à materialidade dos objetos visuais ao buscar analisar a produção de sentido, possibilitando um referencial teórico e metodológico para pesquisas com textos híbridos na área de artes e no ensino da arte. (PILLAR, 2010, p. 1932)

Também o conceito de contágio, referenciado e utilizado no texto de Pillar, reflete o modo como o aspecto da comunicação pode ser percebido na arte contemporânea e no seu ensino, além de estar intimamente ligado ao conceito de visualidade 
apresentado, uma vez que os limites entre as linguagens e os meios estão cada vez mais tênues, colocando-nos mais próximos do contato com a arte. Nas palavras da pesquisadora:

Poderíamos, então, usar o termo contágio para pensar não só a permeabilidade entre as produções da arte contemporânea e da mídia desenho animado, este encontro sensível que torna difusas as fronteiras entre estas duas áreas e promove modificações tanto na arte como na mídia; mas também este encontro do sujeito com as produçôes contemporâneas. [...] Outra forma de contágio presente na contemporaneidade diz respeito as fronteiras difusas entre arte, mídia e cotidiano, em que temas, processos e suportes se mesclam. (Idem, p.1931-1932)

Esse modo de conceber o contágio acaba nos conduzindo a pensar que os projetos transdisciplinares teriam uma afinidade conceitual, principalmente no tocante à permeabilidade, no modo como cada área ou linguagem acaba penetrando, tendo contato com outras. Como é a proposta de Sandra Conceição Nunes e Sandra Regina Ramalho no artigo $A$ complexa busca pela transdisciplinaridade no ensino da arte, publicado no $18^{\circ}$ encontro da ANPAP, uma vez que fala justamente desse caráter permeável, em que as áreas se articulam de modo interligado, apesar de as autoras apontarem apenas para a transdisciplinaridade entre as disciplinas de caráter estético - artes visuais, música e teatro - esse modo de trabalho pode ser utilizado para a elaboração de projetos mais amplos, que visem a uma comunicação entre diferentes áreas do conhecimento.

\section{Considerações finais}

A divisão deste trabalho em três eixos principais se deu como uma alternativa para chegarmos um pouco mais perto de alguns aspectos que têm se mostrado essenciais para pensar a arte contemporânea, e especialmente o ensino de arte que utiliza esse período como conteúdo para a elaboração de seus projetos de ensino e pesquisa. E, chegando ao final desse processo, percebe-se que essa divisão acaba por evidenciar o quanto todas essas questôes estão 
interligadas e podem nos conduzir a outros aspectos e conceitos que ultrapassam os limites deste estudo, evidentemente não seguirei a análise aqui pelo fato de que se tornaria por demasiado generalizante e extenso, o que fugiria da proposta do formato artigo. Por fim, fica evidente que diante do cenário da arte contemporânea e do ensino da arte atual é preciso que encaremos uma mudança de atitudes, tanto no momento em que estamos em sala de aula quanto naqueles em que estamos circulando pelas ruas, ou ainda visitando exposições, pois só com uma postura mais disponível conseguiremos viver e proporcionar experiências plenas de sentido. E essas experiências podem surgir nos momentos mais inusitados e estruturados em inúmeros suportes, criando diversos modos de comunicação, pois, como vimos, os limites para a arte já foram transpostos há bastante tempo.

\section{Referências}

ARCHER, Michael. Arte contemporânea: uma história concisa. Tradução de Alexandre Krug e Valter Lellis Siqueira. São Paulo: Martins Fontes, 2001.

BARBOSA, Ana Mae (Org.). Inquietações e mudanças no ensino da arte. São Paulo: Cortez, 2003.

BRANDÃO, Claudia Mariza Mattos. (Re)Lendo o espaço nas ondas imaginárias do grafitti: contribuições para uma arte/educação contemporânea. In: Anais 33 ${ }^{a}$ Reunião da ANPED, Caxambu, 2010.

CALVINO, Ítalo. As cidades invisíveis. Tradução de Diogo Mainardi. Rio de Janeiro: O Globo; São Paulo: Folha de São Paulo, 2003.

COCCHIARALE, Fernando. Quem tem medo da arte contemporânea? Recife: Fundação Joaquim Nabuco/Editora Massangana, 2006.

COELHO, Gustavo. Pixações na metrópole: uma pedagogia fora da Lei. In: Anais 32 ${ }^{a}$ Reunião da ANPED, Caxambu, 2009 
COHN, Greice. Ensino da arte contemporânea possibilitando mudanças nos modos de percepção da arte. In: Anais $18^{\circ}$ Encontro Nacional da ANPAP, Salvador, BA, 2009.

DUARTE Jr., João Francisco. O sentido dos sentidos: a educação (do) sensível. Curitiba: Criar Edições, 2001.

HONORATO, Cayo. Mediação e sistema da arte. In: Anais $19^{\circ}$ Encontro Nacional da ANPAP, Cachoeira, BA, 2010.

LOSADA, Terezinha. Jakobson, Duchamp e o ensino da arte. In: Anais $19^{\circ}$ Encontro Nacional da ANPAP, Cachoeira, BA, 2010.

MENDONÇA, Vera Rodrigues. O contexto e a mediação da recepção na arte contemporânea. In: Anais $18^{\circ}$ Encontro Nacional da ANPAP, Salvador, BA, 2009.

NUNES, Sandra Conceição. A complexa busca pela transdisciplinaridade no ensino de arte. In: Anais $18^{\circ}$ Encontro Nacional da ANPAP, Salvador, BA, 2009.

PILLAR, Analice Dutra. Contágios entre arte e mídia no ensino da arte. In: Anais $19^{\circ}$ Encontro Nacional da ANPAP, Cachoeira, BA, 2010.

SALOMÉ, Joselia Schwanka. A arte na escola e o conhecimento do sensível. In: Anais $18^{\circ}$ Encontro Nacional da ANPAP, Salvador, BA, 2009.

SCHULTZ, Valdemar. Pichação e grafite: reverberações educacionais. In: Anais 33 ${ }^{a}$ Reunião da ANPED, Caxambu, 2010.

VALENÇA, Kelly Bianca. Arte contemporânea no contexto escolar: ausências e resistências. In: Anais $18^{\circ}$ Encontro Nacional da ANPAP, Salvador, BA, 2009. 